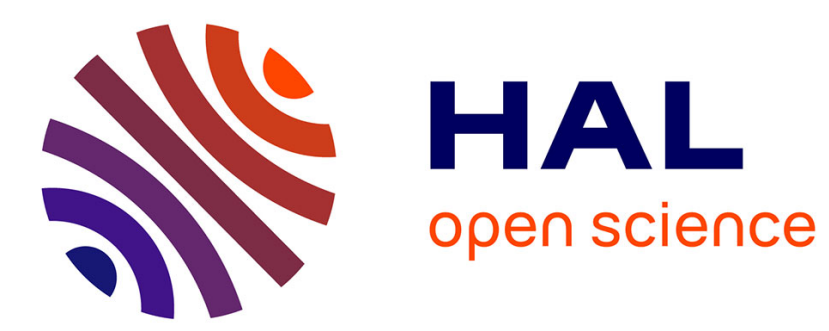

\title{
AUGER TRANSITIONS IN SINGLY AND MULTIPLY IONIZED ATOMS
}

\author{
W. Mehlhorn
}

\section{To cite this version:}

W. Mehlhorn. AUGER TRANSITIONS IN SINGLY AND MULTIPLY IONIZED ATOMS. Journal de Physique Colloques, 1978, 39 (C1), pp.C1-92-C1-98. 10.1051/jphyscol:1978115 . jpa-00217311

\section{HAL Id: jpa-00217311 https://hal.science/jpa-00217311}

Submitted on 1 Jan 1978

HAL is a multi-disciplinary open access archive for the deposit and dissemination of scientific research documents, whether they are published or not. The documents may come from teaching and research institutions in France or abroad, or from public or private research centers.
L'archive ouverte pluridisciplinaire HAL, est destinée au dépôt et à la diffusion de documents scientifiques de niveau recherche, publiés ou non, émanant des établissements d'enseignement et de recherche français ou étrangers, des laboratoires publics ou privés. 


\title{
AUGER TRANSITIONS IN SINGLY AND MULTIPLY IONIZED ATOMS
}

\author{
W. MEHLHORN \\ Fakultät für Physik, Universität Freiburg, D 7800 Freiburg, Germany
}

\begin{abstract}
Résumé. - Les progrès récents intervenus dans l'étude des processus Auger et des processus d'autoionisation par spectroscopie électronique sur des métaux à l'état atomique et sur des atomes multiplement ionisés sont passés en revue.

Les différences entre les spectres observés sur la phase gazeuse et sur la phase solide sont dues à des effets d'état solide. Le cas du cadmium est pris comme exemple. Les transitions super-CosterKronig $3 \underline{p}-3 \underline{d}^{2}$ (notation en trou) et les transitions Coster-Kronig $3 \underline{p}-3 \underline{d} 4 \underline{s}$ ont été étudiées expérimentalement et les résultats obtenus comparés à des calculs atomiques dans le cas du zinc atomique. La largeur expérimentale $\Gamma(3 \mathrm{p})=(2,1 \pm 0,2) \mathrm{eV}$ obtenue pour l'atome libre est en accord avec la valeur obtenue pour le métal à l'état solide, mais est considérablement plus faible que la valeur théorique pour l'atome libre.

Les spectres d'autoionisation du sodium suivant une excitation ou une ionisation en couche $\mathrm{L}$ par différents types de particules sont comparés et discutés. La distribution angulaire non isotropique des électrons émis dans la transition $2 p^{5} 3 s^{2} \quad 2 P_{3 / 2} \rightarrow 2 p^{6}+e^{-}$est comparée avec des calculs théoriques.

Deux exemples de résultats obtenus par spectroscopie Auger sur des atomes multiplement ionisés sont donnés : (1) excitation d'atomes de néon par des ions légers et par des ions lourds ; (2) excitation de projectiles ionisés $\mathrm{Be}^{+}$et $\mathrm{B}^{+}$par collision avec des molécules de $\mathrm{CH}_{4}$. Un effet intense d'alignement des atomes excités a aussi été trouvé dans ce cas.
\end{abstract}

\begin{abstract}
Some recent progress in Auger and autoionizing electron spectrometry of free metal atoms and of multiply ionized atoms is reviewed.

The differences which arise between the spectra of atoms in the gaseous and the solid state are due to solid state effects. This will be shown for $\mathrm{Cd}$ as an example. The super Coster-Kronig transitions $3 \underline{p}-3 \underline{d}^{2}$ (hole notation) and Coster-Kronig transitions $3 \underline{p}-3 \underline{d} 4 \underline{s}$ have been measured and compared with free-atom calculations for free $\mathrm{Zn}$ atoms. The experimental width $\Gamma(3 \mathrm{p})=$ $(2.1 \pm 0.2) \mathrm{eV}$ found for the free atom agrees with the value obtained for solid $\mathrm{Zn}$ but is considerably smaller than the theoretical value for the free atom.

Autoionizing spectra of $\mathrm{Na}$ following an L-shell excitation or ionization by different particles are compared and discussed. The nonisotropic angular distribution of electrons from the transition $2 \mathrm{p}^{5} 3 \mathrm{~s}^{2}{ }^{2} \mathrm{P}_{3 / 2} \rightarrow 2 \mathrm{p}^{6}+\mathrm{e}^{-}$is compared with theoretical calculations.

Two examples for Auger spectrometry of multiply ionized atoms are given : (1) excitation of neon target atoms by light and heavy ions, and (2) excitation of projectile ions $\mathrm{Be}^{+}$and $\mathrm{B}^{+}$ in single gas collisions with $\mathrm{CH}_{4}$. A strong alignment of the excited atoms has also been found here.
\end{abstract}

1. Introduction. - The non-radiative (Auger and autoionizing) transition is an important decay process following an inner shell excitation. Therefore the spectrometry of Auger (and autoionizing) electrons can be used to obtain information about the excitation and deexcitation processes of inner shell vacancies.

Recently Auger electron spectrometry has also been extended to study free metal atoms. These spectra compared to those obtained from atoms in the solid state, exhibit most directly the solid state effects. Since theoretical values of transition probabilities and energies are only available for the free atoms, they can now be compared directly with the experimental results found for free metal atoms. Furthermore, the spectrometry of electrons ejected after the collisional excitation of atoms by low energy electrons or ions, allows one to study not only the states which are excited by optical allowed but also by optical forbidden transitions.

Auger spectra of multiply ionized atoms have been studied in the past mostly for cases where the multiple ionization was induced by photoabsorption or by collision with electrons or light ions. In these processes generally only one outer shell electron is removed during the inner shell ionization (shake off). By energetic heavy ion impact many outer shell electrons can be removed in addition to the ionization of the inner shell electron. Thus heavy ion-atom collisions open the possibility to study the decay of inner shell vacancies in multiply ionized atoms. Information about few-electron systems are of general interest in many fields such as astrophysics and many-electron correlation effects. 
2. Auger and other non-radiative transitions in metal atoms. - Comparison of spectra obtained for atoms in the gaseous and solid state yields directly solid state effects such as energy shifts, broadening of lines, and change of relative intensities. As an example, the $3 \mathrm{~d}-4 \mathrm{~d}^{2}$ Auger spectra of $\mathrm{Cd}$ vapour and solid $\mathrm{Cd}$, both excited by electron impact [1], are shown in figure 1 . Both spectra have been measured
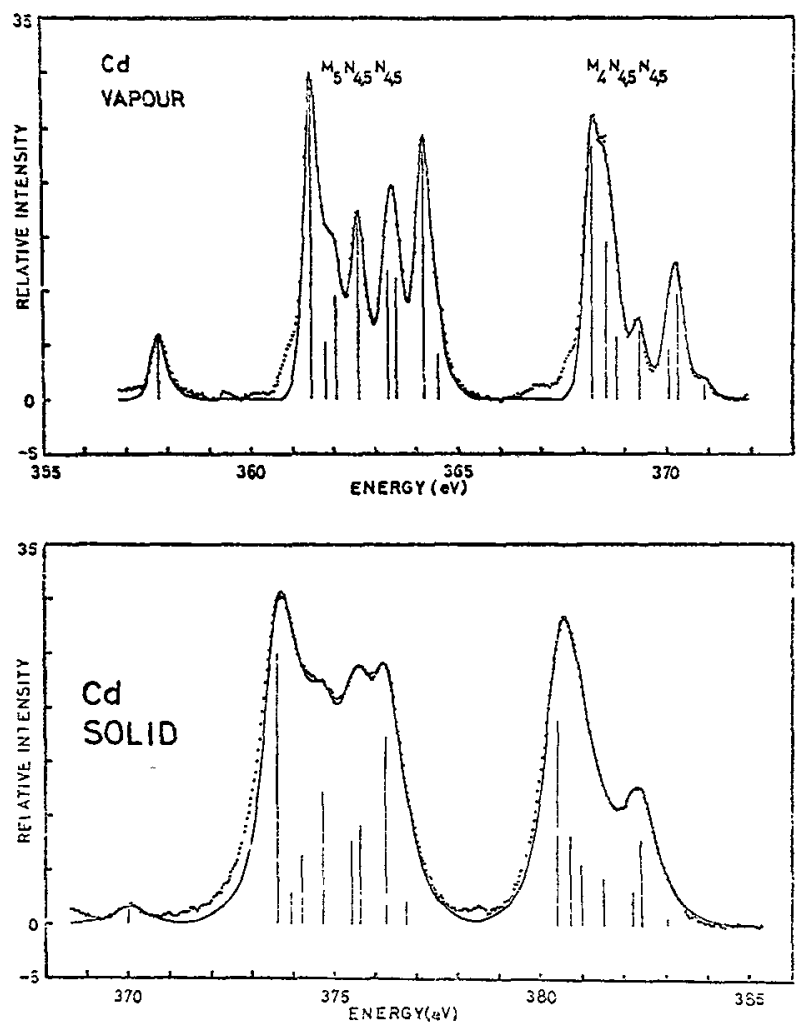

FIG. 1. - 3d-4d $\mathrm{d}^{2}$ Auger spectra of $\mathrm{Cd}$ vapour and solid $\mathrm{Cd}$ [1]. The energy axis are shifted by $12.2 \mathrm{eV}$ relative to each other.

with the same spectrometer under equal experimental conditions, backgrounds of both spectra have been subtracted. As can be seen from figure 1, the spectrum of $\mathrm{Cd}$ vapour is shifted in energy by $12.2 \mathrm{eV}$ to lower values compared to that of solid $\mathrm{Cd}$. Using the scheme of extra-atomic relaxation for the vapour-metal energy shift proposed by Shirley [2] and Kowalczyk et al. [3] the theoretical shift has been evaluated to be $12.7 \mathrm{eV} \mathrm{[1]} \mathrm{in} \mathrm{good} \mathrm{agreement} \mathrm{with} \mathrm{the} \mathrm{experimental}$ value.

The structure of the relative intensity distribution in the spectrum of solid $\mathrm{Cd}$ is very similar to that of $\mathrm{Cd}$ vapour and indicates the quasi-atomic behaviour of doubly ionized final states of $\mathrm{Cd}$ in the solid state. This quasi-atomic appearance of Auger spectra has been found also for $\mathrm{Cu}$ and $\mathrm{Zn}[4,5]$. The decomposition of the spectra into individual lines yielded natural lines widths of $(0.32 \pm 0.05)$ and $(0.79 \pm 0.05) \mathrm{eV}$ for $\mathrm{Cd}$ atoms and for solid $\mathrm{Cd}$, respectively. The broadening of lines by $0.5 \mathrm{eV}$ arises mainly from the different widths of final states in the free atom and the solid. For free $\mathrm{Cd}$ atoms the final state width is negligible and the observed width of $0.32 \mathrm{eV}$ is thus identical to the level width $\Gamma(3 \mathrm{~d})$. The theoretical free-atom value, $\Gamma(3 \mathrm{~d})_{\text {theor }}=0.44 \mathrm{eV}[6]$, is somewhat larger than the experimental value.

Coster-Kronig (CK) and super Coster-Kronig (sCK) transitions are of special importance because of their much larger transition probabilities compared to Auger transitions. The broad level width $\Gamma(4 \mathrm{p})$ for $45 \leqslant Z \leqslant 70$ ranging from $2 \mathrm{eV}$ up to $20 \mathrm{eV}$ are mostly due to $4 \mathrm{p}-4 \mathrm{~d}^{2}$ sCK transitions [7-11]. On the contrary, the $\mathrm{sCK}$ transitions $3 \mathrm{p}-3 \mathrm{~d}^{2}$ lead only to level widths $\Gamma(3 p)$ of $1-5 \mathrm{eV}[6,4]$. This dramatic difference in level widths can be best seen in the photoelectron lines of the $4 \mathrm{p}$ shell of $\mathrm{Cd}$ and the $3 p$ shell of $\mathrm{Zn}$ (Fig. 2).

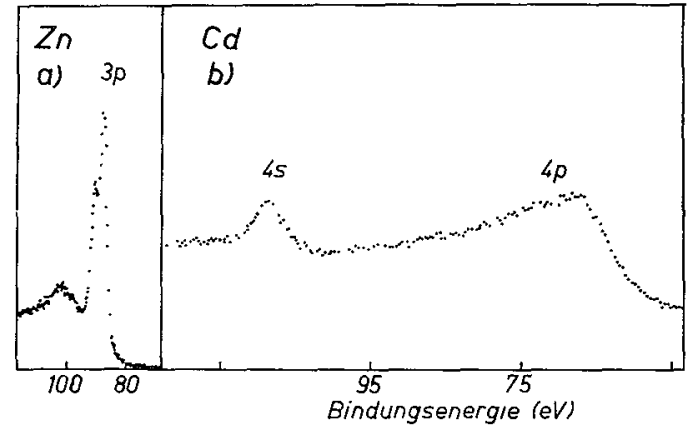

FIG. 2. - Photoelectron spectra of $3 p$ shell of solid $\mathrm{Zn}$ and $4 s, 4 p$ shells of solid $\mathrm{Cd}$ using Al $\mathrm{K} \alpha$ radiation [12].

It is interesting to note that the results of calculations by McGuire [10] and by Chen et al. [11] agree rather well with each other and with experimental values for $\Gamma\left(4 \mathrm{p}_{1 / 2}\right)$ and $\Gamma\left(4 \mathrm{p}_{3 / 2}\right)$ for $46 \leqslant Z \leqslant 50[11]$ On the other hand, the values for $\Gamma\left(3 \mathrm{p}_{1 / 2}\right)$ and $\Gamma\left(3 p_{3 / 2}\right)$ found by McGuire [6] are larger by a factor of two than those calculated by Chen $e t$ al. [4]. In the two sets of calculations different atomic potentials were used, a $V\left(4 \mathrm{p}^{-1}\right)$ or $V\left(3 \mathrm{p}^{-1}\right)$ potential by McGuire $[10,6]$ and a neutral free-atom potential by Chen et al. [11, 4]. Also it was found that the sCK transition probabilities are very sensitive to the energy of ejected electrons. From that it appeared that the state of a $3 \mathrm{~d}$ electron in the solid-state atom involved in the $3 \mathrm{p}-3 \mathrm{~d}^{2}$ transition is better described by the $3 \mathrm{~d}$ wave function of a neutral atom than of an atom with a $3 p$ vacancy. This solid state effect should be absent in the free atom.

Therefore we measured the width $\Gamma(3 \mathrm{p})$ of free $\mathrm{Zn}$ atoms via the line width of $\mathrm{sCK}$ transitions $3 p-3 \underline{d}^{2}$ [13] (see Fig. 3). A detailed calculation assuming $j j$-coupling for the initial $3 p$ vacancy and intermediate coupling for the final $3 \mathrm{~d}^{2}$ and $3 \mathrm{~d} 4 \mathrm{~s}$ vacancies and using McGuire's matrix elements [6] yielded our theoretical relative intensities (bar spectrum of Fig. 3). Assuming Lorentzian line shapes 


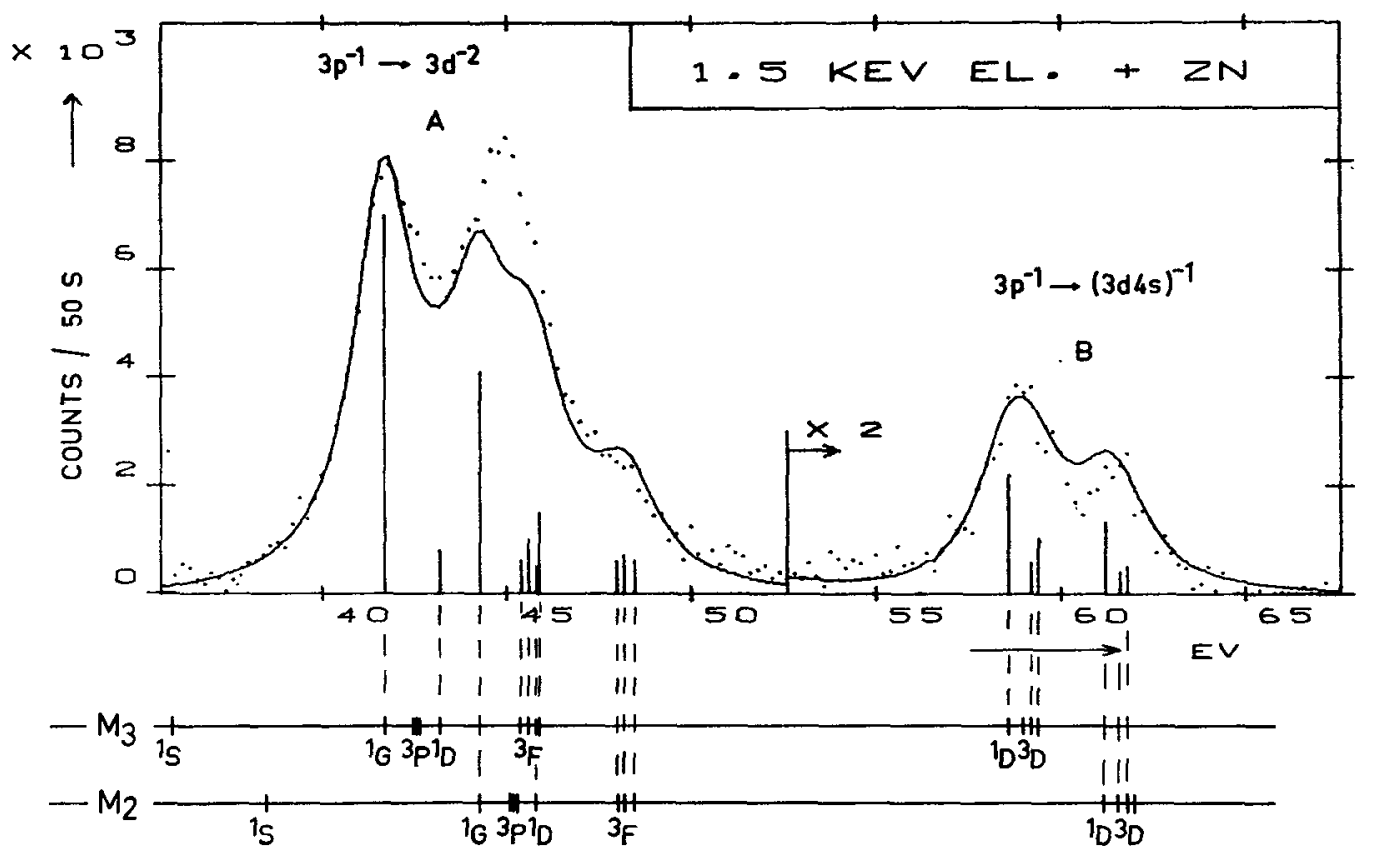

Fig. 3. - 3p-3d $\mathrm{d}^{2} \mathrm{sCK}$ transitions and $3 p-3 d 4 s$ CK transitions of free $\mathrm{Zn}$ atoms. The bar spectrum gives the theoretical relative intensities calculated in $\mathrm{jj}$-coupling for the $3 \mathrm{p}$ vacancy and intermediate coupling for the final vacancies using McGuire's matrix elements [6].

for the individual components the best fit to the experimental intensity distribution yielded a level width $\Gamma\left(3 \mathrm{p}_{1 / 2}\right)=\Gamma\left(3 \mathrm{p}_{3 / 2}\right)=(2.1 \pm 0.2) \mathrm{eV}$. This agrees well with the solid state values (see Fig. 4) showing that the total transition rate changes only little between the free $\mathrm{Zn}$ atoms and the $\mathrm{Zn}$ atoms in the solid state. In figure 4 also values calculated most recently by Howat [14] for a $V\left(3 \mathrm{p}^{-1}\right)$ potential and by Ohno and Wendin [15] for a $V\left(3 \mathrm{~d}^{-2}\right)$ as well as a neutral potential are shown. The value from Howat also overestimates the $3 p$ level width of the free $\mathrm{Zn}$ atom. Ohno and Wendin calculated level widths for $Z$ ranging from 32 to 40 , the values for $Z=35$ and 36 , calculated for a $V\left(3 \mathrm{~d}^{-2}\right)$ potential, agree well with experimental widths found for $\mathrm{Br}$ (in $\mathrm{Br}_{2}$ ) and $\mathrm{Kr}$ atoms [16]. Straight line extrapolation to $Z=30$

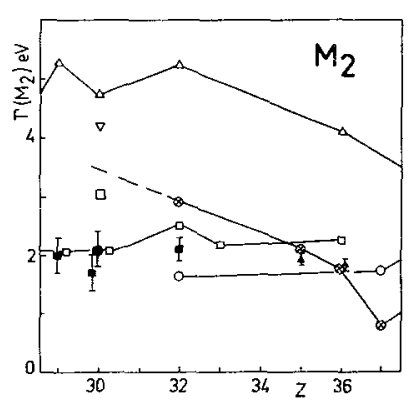

(a)

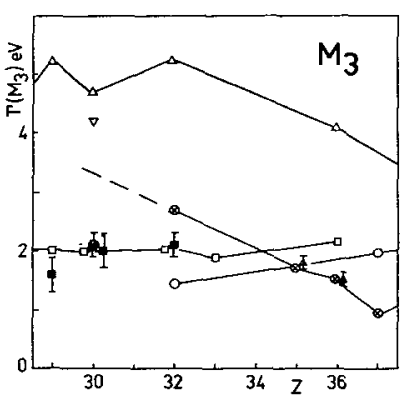

(b)
FIG. 4. - Comparison of experimental and theoretical widths of a) a $3 \mathrm{p}_{1 / 2}=\mathrm{M}_{2}$ and $b$ ) a $3 \mathrm{p}_{3 / 2}=\mathrm{M}_{3}$ vacancy state. Experiment : $\Phi=$ free atom $(\mathrm{Zn})[13], \bar{\Lambda}=$ free atom $(\mathrm{Br}, \mathrm{Kr})[16]$, $\tau=$ solid state [4]. Theory: Neutral atom potential $: \square=[4]$, $\stackrel{\circlearrowleft}{\bigcirc}=[15] ; V\left(3 \mathrm{p}^{-1}\right)$ potential : $\Delta=[6], \nabla=[14], \square=[4]$; $V\left(3 \mathrm{~d}^{-2}\right)$ potential $: \otimes=[15]$. (dashed curve in Fig. 4) would lead to a value which also greatly overestimates the $3 p$ level width. Based on McGuire's values, the dotted curve seems to be a better extrapolation, which now yields a $3 p$ level width in reasonable agreement with our experimental value. Additional calculations for $Z=30$ will clarify this [17].

Recently autoionizing electron spectra of free alkali and alkaline earth atoms have been investigated extensively using not only electron but also $\mathrm{H}^{+}$ and $\mathrm{He}^{+}$impact excitation ( $\mathrm{Li}[18], \mathrm{Na}[18,19,20]$, $\mathrm{K}[21,22], \mathrm{Mg}[23,24], \mathrm{Ca}[25], \mathrm{Sr}$ [25], Ba [26]). In collision processes, depending on the projectile and its energy, not only single-electron dipole, quadrupole and electron exchange excitations but also a large variety of double electron excitations can occur, especially in $\mathrm{He}^{+}$and heavy ion-atom collisions. Here the quantitative analysis of ejected electron spectra gives a detailed information about the various excitation channels and their cross sections.

In figure 5 different spectra of ejected electrons for $\mathrm{e}^{-}\left(50 \mathrm{eV}\right.$ [19], $16 \mathrm{keV}$ [20]), $\mathrm{He}^{+}(50,300 \mathrm{keV}$ [18]), and $\mathrm{He}^{+}(300 \mathrm{keV}$ [18]) on $\mathrm{Na}$ are shown. For high energy electron impact mainly single electron dipole excitations occur, e. g. 2 p $\rightarrow 3$ s (lines $4 / 5$ ) and $2 \mathrm{p} \rightarrow n \mathrm{~d}(n \geqslant 3)$, $n$ s $(n \geqslant 4)$ (lines 13,14 and higher). Line 1 corresponds to the $\mathrm{CK}$ transition following the 2 s-ionization. $2 \mathrm{p} \rightarrow 3 \mathrm{p}$ quadrupole excitations (lines 7-11) become increasingly important for low electron energies and for $\mathrm{H}^{+}$and $\mathrm{He}^{+}$collisions. Two-electron excitation processes, e.g. $2 s^{2} 2 p^{6} 3 s \rightarrow 2 s 2 p^{6} 3 p$ (lines 2) and $2 s^{2} 2 p^{6} 3 s \rightarrow 2 s$ $2 \mathrm{p}^{6} 4 \mathrm{~s}$ (lines 6) are more important in ion-atom 


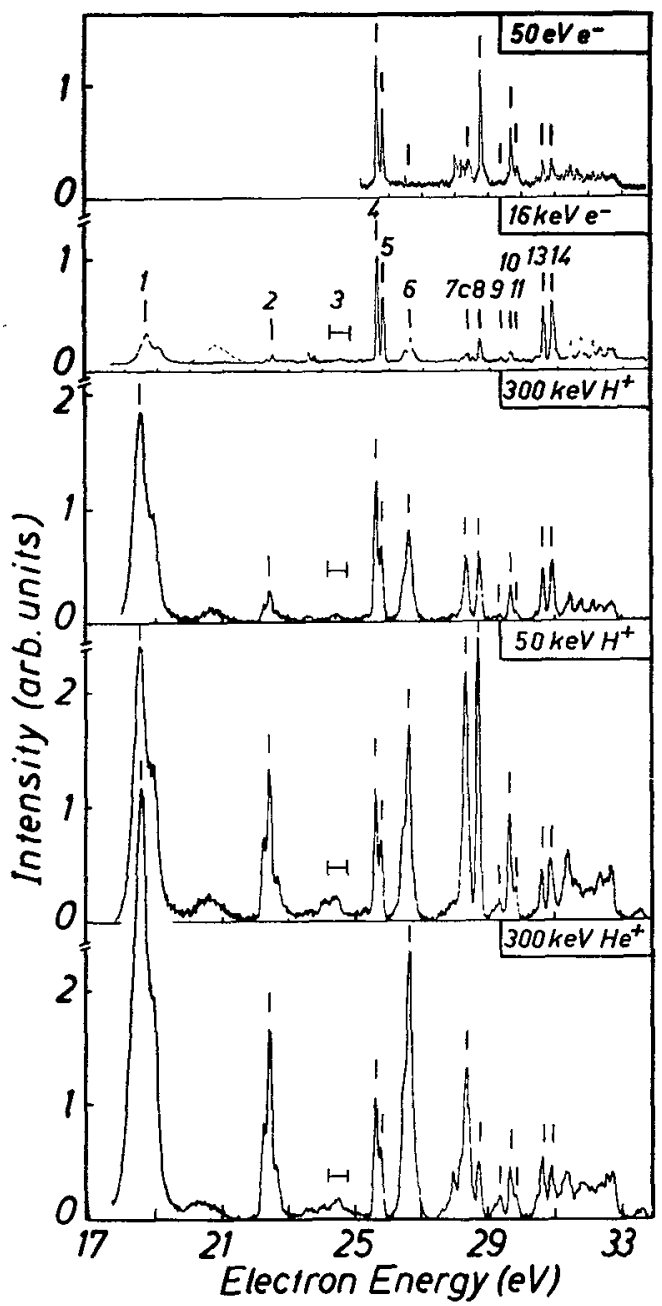

FIG. 5. - Comparison of ejected electron spectra for different excitation modes : $50 \mathrm{e}^{-}+\mathrm{Na}$ [19], $16 \mathrm{keV} \mathrm{e}^{-}+\mathrm{Na}$ [20], 50, $300 \mathrm{keV} \mathrm{H}++\mathrm{Na}[18], 300 \mathrm{keV} \mathrm{He}^{+}+\mathrm{Na}$ [18]. For assignment of lines see text.

collisions as can be clearly seen in figure 5 . Also it is interesting to note that the $2 \mathrm{~s}$ ionization probability (line 1) relative to the $2 p \rightarrow 3$ s excitation probability (lines $4 / 5$ ) is much larger for ion impact and increases for decreasing velocities of $\mathrm{H}^{+}$or $\mathrm{He}^{+}$.

An even more detailed information about the collision process can be obtained from the nonisotropic angular distribution of ejected electrons as the result of an alignment of the excited atoms [27]. Only states with $J>\frac{1}{2}$ can be aligned. The general form of the angular distribution of ejected autoionizing electrons has been given by Balashov et al. [28, 29] and will be nonisotropic also for $J=\frac{1}{2}$ states, due to the interference between the two channels of autoionization and direct ionization. For $\mathrm{Na}$, the amplitude for direct ionization is much smaller than that for the autoionizing transition [30], thus the angular distribution depends only on the decay of the autoionizing state. That is, the ${ }^{2} P_{1 / 2}$ state decays isotropically and the angular distribution of electrons from the decay of the ${ }^{2} \mathrm{P}_{3 / 2}$ state $\left(2 \mathrm{p}^{5} 3 \mathrm{~s}^{2}{ }^{2} \mathrm{P}_{3 / 2} \rightarrow 2 \mathrm{p}^{6}\right.$ $\left.{ }^{1} \mathrm{~S}+\mathrm{e}^{-}\right)$is given by

$$
I(\theta)=I_{0}\left(1+A_{2} P_{2}(\cos \theta)\right),
$$

where $P_{2}(\cos \theta)$ is the second Legendre polynomial. The anisotropy coefficient $A_{2}$ contains the information about the excitation process and is given for the present case by

$$
A_{2}=(Q(2 \mathrm{p} 0)-Q(2 \mathrm{p} 1)) /(Q(2 \mathrm{p} 0)+2 Q(2 \mathrm{p} 1)),
$$

where $Q\left(2 \mathrm{p} m_{l}\right)$ is the single electron cross section for excitation $2 \mathrm{pm} m_{l} \rightarrow 3 \mathrm{~s} 0$.

Nonisotropic distributions have been measured for impact ionization by electrons $(500-4000 \mathrm{eV}$ [20] and $150 \mathrm{eV}$ [19]), $\mathrm{H}^{+}\left(50-300 \mathrm{keV}\right.$ [31]) and $\mathrm{He}^{+}$ $\left(89 \mathrm{keV}\right.$ [31]). Figure 6 shows the doublet $2 \mathrm{p}^{5} 3 \mathrm{~s}^{2}$ ${ }^{2} \mathrm{P}_{3 / 2},{ }^{2} \mathrm{P}_{1 / 2} \rightarrow 2 \mathrm{p}^{6}+\mathrm{e}^{-}$(lines $4 / 5$ of Fig. 5) for $4 \mathrm{keV}$ primary electrons and $\theta=150^{\circ}$ as an example. In figure 7 the $A_{2}$-coefficients, evaluated from the nonisotropic intensity of the ${ }^{2} \mathrm{P}_{3 / 2}$ component using

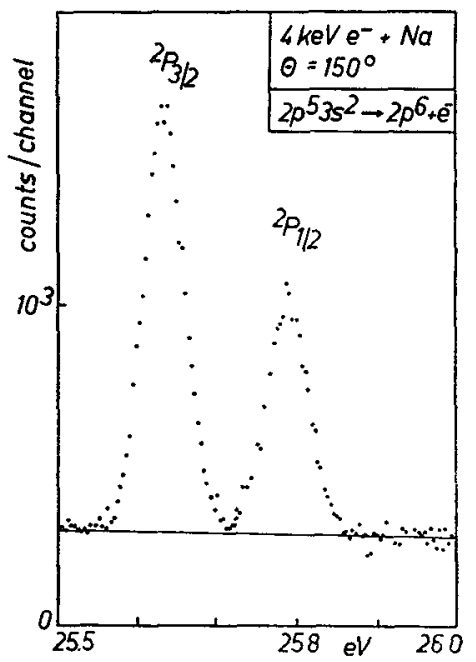

FIG. 6. - Lines 4 and $5\left(2 p^{5} 3 s^{2} 2 P_{3 / 2},{ }^{2} P_{1 / 2} \rightarrow 2 p^{6}+e^{-}\right)$of figure 5 measured with high resolution at $\theta=150^{\circ}$.

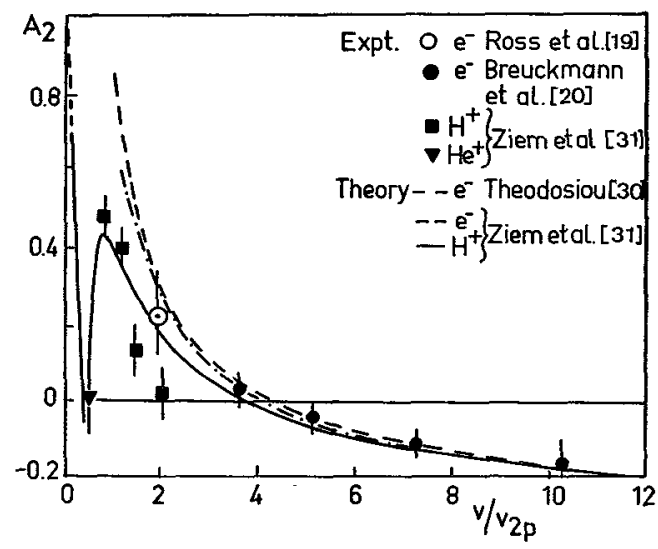

FIG. 7. - Experimental and theoretical $A_{2}$-coefficients of the $2 p^{5} 3 s^{2} 2 P_{3 / 2} \rightarrow 2 p^{6}+e^{-}$transition in $\mathrm{Na}$ excited by different particles as function of the collision velocity $v$ in units of the mean velocity $v_{2 p}$ of the $2 \mathrm{p}$ electron of $\mathrm{Na}$. 
eq. (1), are compared with theoretical values calculated by Theodosiou for electron impact [30] and by Ziem et al. [31] for electron and proton impact using first Born approximation and Hartree-Slater wave functions. It is interesting to note that the theoretical $A_{2}$ values are different for electron and proton impact. Unfortunately the experimental value found by Ross et al. [19] for $150 \mathrm{eV}$ electrons has too large an error to confirm this. The structure of the $A_{2}$-curve predicted theoretically for proton impact at $v / v_{2 \mathrm{p}}=0.4$ has been observed experimentally by Ziem et al. [31].

3. Auger transitions in multiply ionized atoms. Auger spectra of multiply ionized atoms in outer shells are rather complex due to the large number of initial and final states. Only in cases of few vacancies in otherwise filled shells or few electrons outside filled shells, the spectra can be quantitatively analysed, yielding information about the primary collision process and the decay process. As an example figure 8 shows K-Auger spectra of the neon atom excited by different collision processes [32]. It can be seen, that the $\mathrm{K}$-Auger spectrum induced by $4.2 \mathrm{MeV}$ protons [33] exhibits a rather simple spectrum which consists primarily of diagram lines (due to transi-

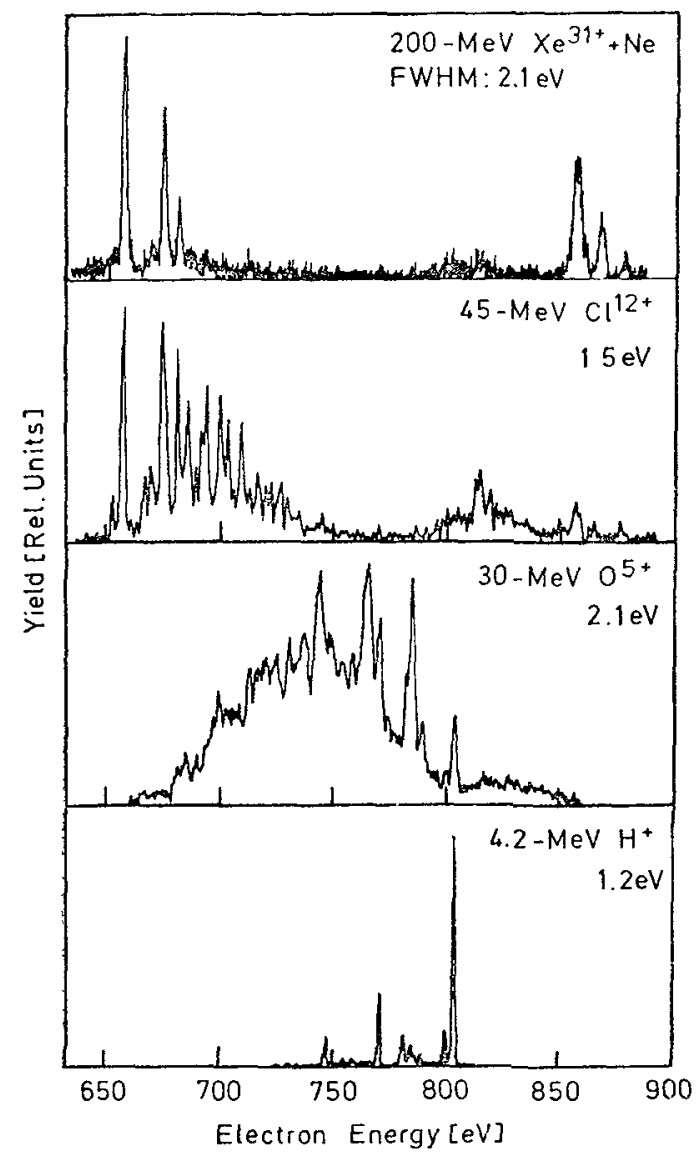

Fig. 8. - Neon $\mathrm{K}$ Auger spectra excited by various projectiles : $4.2 \mathrm{MeV} \mathrm{H}^{+}$[33], $30 \mathrm{MeV} \mathrm{O}^{5+}$ [34], $45 \mathrm{MeV} \mathrm{Cl}^{12+}$ [35] and $200 \mathrm{MeV} \mathrm{Xe}^{31+}[36]$. tions in the atom which is singly ionized in the inner shell) and weak satellite lines (mostly KL-LLL). The $\mathrm{K}$ Auger spectra induced by $30 \mathrm{MeV} 0^{5+}[34]$ and $45 \mathrm{MeV} \mathrm{Cl}^{12+}$ ions [35] show a very complex structure due to the overlap of satellite lines resulting from various charge stages of the multiply ionized neon atom in the $L$ shell. The main energies of these satellite lines decrease for increasing number of $\mathbf{L}$ shell vacancies. The lines observed at higher energies than the diagram lines are probably due to double $\mathrm{K}$ shell excitations. Only in the case of $200 \mathrm{MeV} \mathrm{Xe} \mathrm{X}^{31+}$ on neon [36] the $K$ Auger spectrum is rather simple and consists only of a few lines. A detailed analysis has shown that these lines are mostly from the Li-like neon ion [36]. Figure 9 shows the low energy part of this spectrum measured with high resolution.

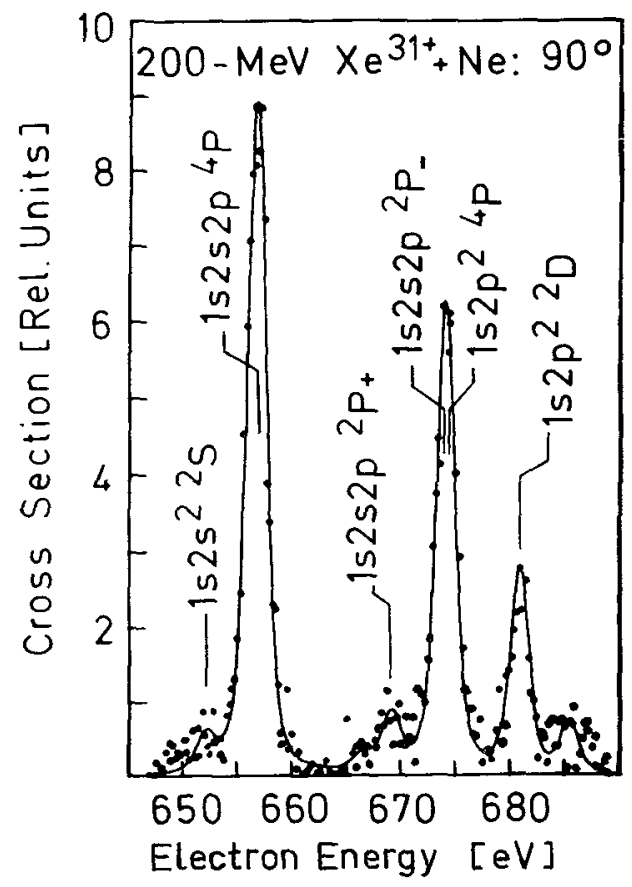

Fig. 9. - Low-energy part of Ne K Auger spectrum produced in $200 \mathrm{MeV} \mathrm{Xe} \mathrm{Xe}^{31+}+\mathrm{Ne}$ collision [36].

From this spectrum the following information can be obtained: The experimental transition energies can be checked against theoretical values. The relative intensities of lines (statistical or non-statistical population), and the nonisotropic angular distribution of line intensities [36] yield information about the collision process itself.

All high resolution electron spectra produced in heavy ion-atom collisions so far have been obtained only from the excited target atoms. Doppler broadening occuring in the spectra of the projectile ions have prevented the high resolution spectrometry for these ions. By selecting small observation angles $\left(6.4^{\circ}\right)$ the Doppler broadening could be minimized resulting in almost as high resolution spectra as those obtained for target atoms. Figure 10 shows, 

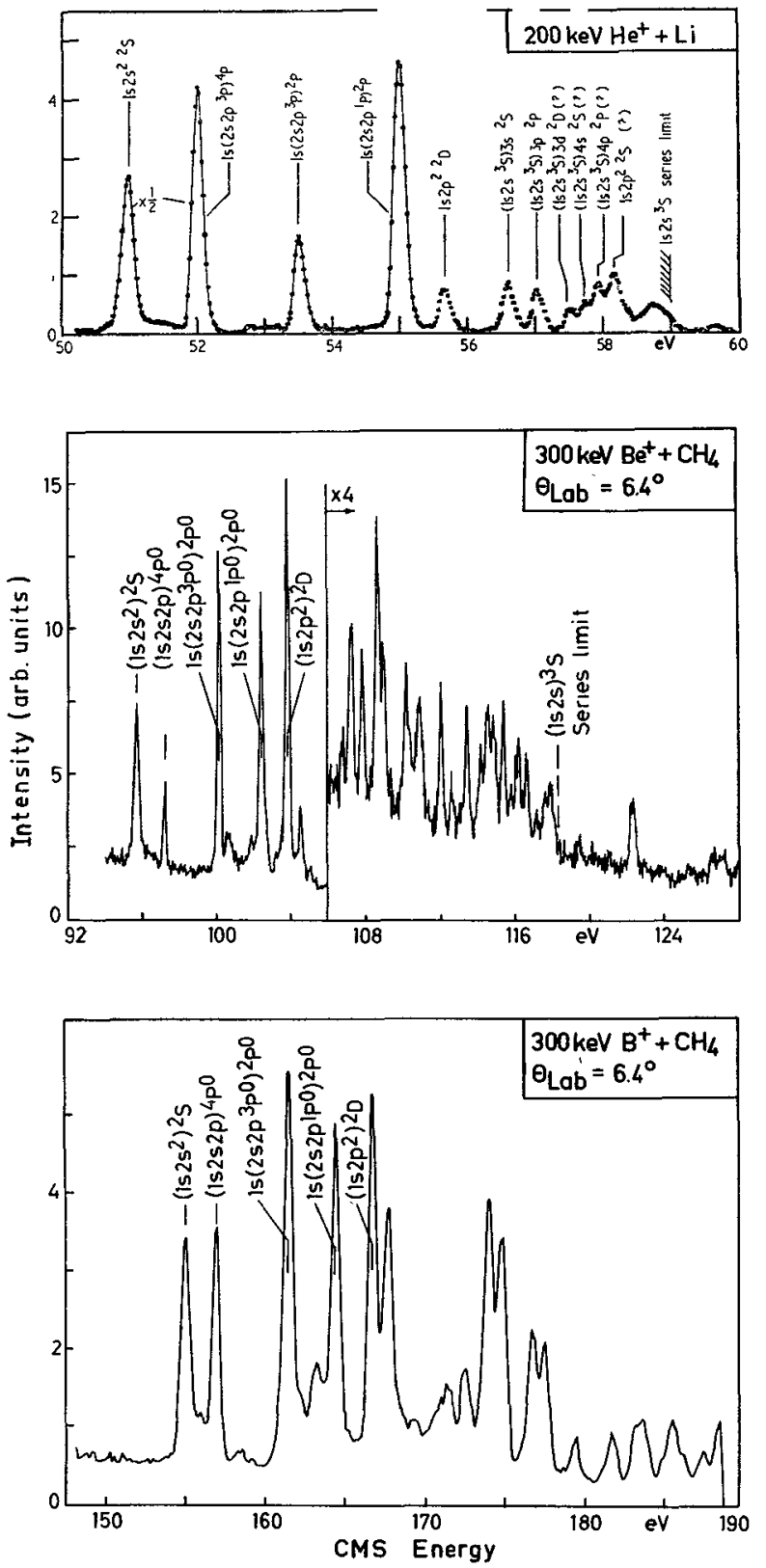

Fig. 10. - Ejected electron spectra of Li-like Be and B projectiles excited in $300 \mathrm{keV} \mathrm{Be}{ }^{+}$and $\mathrm{B}^{+}$collisions on $\mathrm{CH}_{4}$ [40] compared to the electron spectrum of $\mathrm{Li}$ produced in $200 \mathrm{keV}$ $\mathrm{He}^{+}+\mathrm{Li}[18]$.

as an example, the autoionizing electron spectra of Li-like $\mathrm{Be}^{+}$and $\mathrm{B}^{++}$projectile atoms excited in $300 \mathrm{keV} \mathrm{Be}{ }^{+}$or $\mathrm{B}^{+}$collisions on $\mathrm{CH}_{4}$ [37-40]. For comparison, the spectrum of $\mathrm{Li}$ target atoms excited by $200 \mathrm{keV} \mathrm{He}^{+}$[18] is also plotted. In the spectra of $\mathrm{Li}$-like $\mathrm{Be}^{+}$and $\mathrm{B}^{++}$all lines up to $1 \mathrm{~s}$ $2 \mathrm{p}^{2}{ }^{2} \mathrm{D}$ are clearly resolved and have been identified. It has been found that the relative line intensities in all three spectra vary with the energy of the projectile particle.

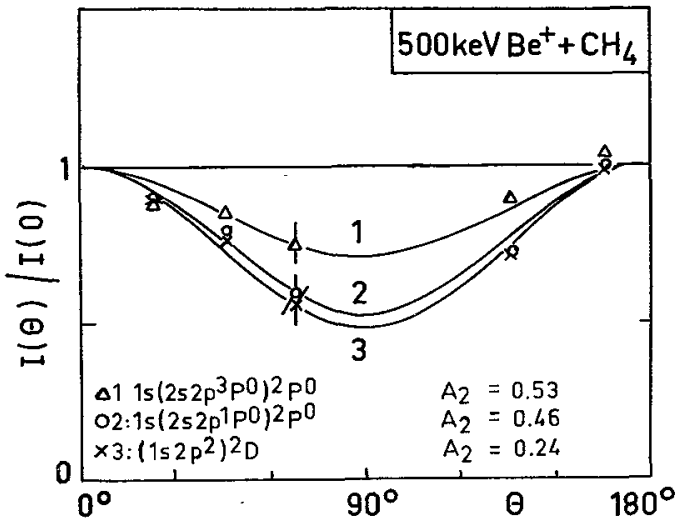

FIG. 11. - Angular distributions of ejected electrons from Lilike $\mathrm{Be}^{+}$ions excited in $500 \mathrm{keV} \mathrm{Be}{ }^{+}-\mathrm{CH}_{4}$ collisions [39]. The $\mathrm{A}_{2}$ values have been evaluated using eq. (1).

Also the line intensities show in most cases a nonisotropic angular distribution. In figure 11 the angular distribution of three lines of $\mathrm{Be}^{+}$are plotted yielding a rather strong alignment of the excited $\mathrm{Be}^{+}$ions [37]. The $A_{2}$ coefficients given in figure 11 were evaluated using eq. (1). Also for the states of $\mathrm{Li}$ excited by $200 \mathrm{keV} \mathrm{He}^{+}$a strong alignment was found [18] to be $A_{2}=-0.13,0.89$ and 0.63 for $1 \mathrm{~s} 2 \mathrm{~s} 2 \mathrm{p}{ }^{4} \mathrm{P}$, $1 \mathrm{~s}\left(2 \mathrm{~s} 2 \mathrm{p}{ }^{3} \mathrm{P}\right){ }^{2} \mathrm{P}$, and $1 \mathrm{~s}\left(2 \mathrm{~s} 2 \mathrm{p}{ }^{1} \mathrm{P}\right){ }^{2} \mathrm{P}$ lines, respectively. Note that the mechanism to excite the ${ }^{2} \mathrm{P}$ states is preferentially by a $1 \mathrm{~s} \rightarrow 2 \mathrm{p}$ excitation whereas the ${ }^{4} \mathrm{P}$ state is excited only by electron exchange. As in the case of $\mathrm{Na}$ (see Fig. 7), one expects an energy dependence of the $A_{2}$-coefficient. Thus the angular measurements of autoionizing electrons give a rather detailed information about the excitation process.

These examples clearly demonstrate that electron spectrometry of multiple ionized atoms will become an important tool studying the various excitation mechanisms in heavy ion-atom collisions.

\section{References}

[1] Aksela, S., Aksela, H., Vuontisjarvi, M., Vayrynen, J. and LÄHTEENKORVA, E., J. Electron Spectrosc. Relat. Phenom. 11 (1977) 137.

[2] Shirley, D. A., Phys, Rev. A 7 (1973) 1520.

[3] Kowalczyk, S. P., Pollak, R. A., McFeely, F. R., LeY, L. and ShuRLeY, D. A., Phys. Rev. B 8 (1973) 2392.

[4] Yin, L. I., Adler, I., Tsang, T., Chen, M. H., Ringers, D. and Crasemann, B., Phys. Rev. $A 9$ (1974) 1070.
[5] Aksela, S., Väyrynen, J. and Aksela, H., Phys. Rev. Lett. 33 (1974) 999.

[6] McGuire, E. J., Phys. Rev. A 5 (1972) 1043. and Sandia Laboratories Report No. SC-RR-710835, unpublished.

[7] Kowalczyx, S. P., Ley, L., Martin, R. L., McFiely, F. R., ShIRLEY, D. A., Faraday Discuss. Chem. Soc. (Vancouver, B. C.) July 15-17 (1975). 
[8] GeıIus, U,, J. Electron. Spectrosc. Relat. Phenom. 5 (1974) 985.

[9] Wendin, G., and Ohno, M., Proc. of the 2nd Conf. Inner Shell Ioniz. Phenom. (ed. W. Mehlhorn and R. Brenn, University of Freiburg) 1976, p. 166, and Phys. Scr. 14 (1976) 148.

[10] MCGuire, E. J., Phys. Rev. A 9 (1974) 1840.

and Sandia Laboratories Report No. Sand-175-0443, unpublished.

[11] Chen, M. H., Crasemann, B., Yin, L. I., Tsang, T. and ADLer, I., Phys. Rev. A 13 (1976) 1435.

[12] KowalczYK, S. P., Ph. D. Thesis, University of California, 1976.

[13] Hausamann, D., Breuckmann, B. and Mehlhorn W., Abstracts of Contr. Papers of X ICPEAC (Paris) 1977, p. 208.

[14] HowAT, G., private communication, 1977.

[15] Ohno, M. and Wendin, G., Submitted to Solid State Commun.

[16] Svensson, S., Martensson, N., Basilier, E., Malmevist, P. A., Gelius, U. and Siegrahn, K., Phys. Scr. 14 (1976) 141.

[17] WeNDIN, G., private communication, 1977.

[18] Stolterfoht, N., Proc, of 2nd Int. Conf. Inner Shell Ion. Phenom. (ed. W. Mehlhorn and R. Brenn, Universität Freiburg) 1976, p. 42.

[19] Ross, K. J., Ottley, T. W., Pejeev, V. and Rassi, D., J. Phys. B 9 (1976) 3237.

[20] Breuckmann, E., Breuckmann, B., Schmitz, W. and Mrhlhorn, W., J. Phys. B 10 (1977) 3135.

[21] Ottrey, T. W. and Ross, K. J., J. Phys. B 8 (1975).

[22] Krummacher, S., Master Thesis, Universität Freiburg, 1976.

[23] BreuckmanN, B., Schmidt, V. and Schmitz, W., J. Phys. B 9 (1976) 3037.
[24] Rassi, D., Pejcev, V., Ottley, T. W. and Ross, K. J., J. Phys. B 10 (1977) 2913.

[25] Schmitz, W., BreuckmanN, B., Mrhl.horn, W., J. Phys. $B 9$ (1976) L 493.

[26] BreuckmanN, B., Ph. D. Thesis, Universität Freiburg, 1977.

[27] Cleff, B. and Mehlhorn, W., J. Phys. B 7 (1974) 593.

[28] Balashov, V. V., LipovetsKy, S. S. and SenashenKo, V. S., Sov. Phys. JETP 36 (1973) 858.

[29] Lipovetsky, S. S. and Senashenko, V. S., J. Phys. B 7 (1974) 693.

[30] Theodosiou, C. E., Phys. Rev. A (1977), to be published. and $J$. Phys. $B 10$ (1977) L 253.

[31] Ziem, P., Morgenstern, R. and Stolterfoht, N., Abstracts of Contr. Papers, X. ICPEAC (Paris) 1977, p. 1002.

[32] Stolterfoht, N., Invited talk at Fourth Conference on the Application of Small Accelerators (Public. No. 76 CH 117-9 NTS, Denton, Texas) October 1976.

[33] Stolterfoht, N., Gabler, H. and Leithäuser, U., Phys. Lett. 45A (1973) 351.

[34] Burch, D., Stolterfoht, N., Schneider, D., Wiemann, H. and Risley, J. S., Nuclear Physics Annual Report 1974 (University of Washington, Seattle, 1975) unpublished.

[35] Schneider, D., Moore, C. F. and Johnson, B. M., J. Phys. B 9 (1976) L 153.

[36] Stolterfoht, N., Schneider, D., ManN, R. and GroeneVeLD, K. O., J. Phys. B 10 (1977) L 281.

[37] Rødrro, M., Bruch, R., BisgaARD, P., J. Phys. B 9 (1977) L 825.

[38] Rødbro, M., Bruch, R., Bisgaard, P., Dahl, P. and FASTRUP, B., J. Phys. B 10 (1977) L 483.

[39] Bisgaard, P., Bruch, R., Dahl, P., Fastrup, B. and RødBro, M., Abstracts of Contr. Papers, X. ICPEAC, Paris, 1977, p. 1022, 1024.

[40] BruCh, R., Private communication, 1977. 